\title{
Anita Anota. El antropólogo en al aldea (penal y burocrática)
}

\author{
Deborah Daich e Mariana Sirimarco
}

resumo Frequentemente, as anotaçóes de campo são produto tanto daquilo que o antropólogo considera importante anotar quanto daquilo que o outro acha importante ser anotado pelo antropólogo. Este trabalho visa refletir acerca desse processo específico do trabalho de campo. Não necessariamente para investigar as questōes epistemológicas relativas à construção de tais anotaçóes, mas para ensaiar algumas consideraçóes sobre a relação que a própria ação de anotar configura entre o observador e o observado. Este trabalho propóe uma trajetória pelos âmbitos de pesquisa das autoras - o judiciário e o policial - e pelas questóes levantadas por essa atividade em tais âmbitos. Trata-se de pôr em diálogo os nossos trabalhos de campo e de experimentar, a partir do contraste entre distintas experiências, o esboço de uma leitura a respeito do tom que, nesses domínios, adquire o próprio ato de registrar no papel.

palavras-chave Trabalho de campo. Registros de campo. Anotar. Âmbito judiciário. Âmbito policial.

\section{Sobre el escribir y el anotar}

La anécdota es ampliamente conocida en el ambiente antropológico. Después de mucho ver al antropólogo tomar apuntes en su cuaderno de campo, el jefe nhambiquara aparece, ante su grupo, también con lápiz y papel. No sabe escribir (el antropólogo que refiere la historia dice que no sabe), pero garabatea signos en la hoja en blanco. Luego los lee, ante la tri- bu y ante el propio antropólogo. Podría decirse que remeda el hacer del antropólogo, que copia lo que el otro hace. Mejor dicho: que copia lo que ve en el otro como fuente de prestigio y de poder. Que disputa, él que al fin de cuentas es el jefe, el campo de las actuaciones y las competencias (Lévi-Strauss, 1973).

Ese gesto mimético - seguramente serio esconde, sin embargo, el bosquejo de una parodia. Lo esconde tal vez para nosotros: es difícil no ver, en el trazo de esos garabatos, una distancia crítica. Los dibujos sin sentido del jefe actúan exageradamente la norma - exageradamente porque el antropólogo nos dice que él la norma no la sabe - y la ponen, de este modo, en evidencia. Sus dibujos valen tanto como las palabras escritas del antropólogo. Ambas son formas de escritura, si entendemos que lo que el jefe hace no apunta a lo escrito sino a su acto: al ejercicio de un mecanismo. Justamente porque no le resulta necesario saber para escribir, la imitación se vuelve parodia. Anclada en un vacío de conocimiento gráfico, la repetición se instala fácilmente como inversión irónica (Hutcheon apud Nagore, 1997). El jefe escribe. $\mathrm{O}$ al menos desnuda una faceta clave de la escritura etnográfica: aquella que la inviste de autoridad.

Es en torno a este sentido que se desenvuelve el presente artículo. En torno a la escritura etnográfica y sus implicancias en el contexto del trabajo de campo. Ya Geertz (2000) dijo que lo que el antropólogo principalmente hace es escribir o, más precisamente, "inscribir" dis- 
cursos sociales. Así, la escritura antropológica es capaz de fijar "lo dicho" de forma tal que aquellos discursos sociales recogidos en el campo adquieran, por medio de su inscripción, un carácter permanente que los hace pasibles de ser consultados una y otra vez. Y en dicha inscripción, la "descripción etnográfica" - sugiere Geertz - la observación, el registro y el análisis/ interpretación aparecen íntimamente ligados puesto que no pueden considerarse operaciones autónomas.

Siguiendo a Geertz, Cardoso de Oliveira distingue dos etapas de la investigación: el antropólogo estando ahi y el antropólogo trabajando estando aquí. En esos términos, sugiere el autor, el mirar y oír serían parte de la primera etapa y el escribir de la segunda; el escribir estando aquí, fuera de la situación de campo, cumpliría su más alta función cognitiva, realizando el proceso de textualización de los fenómenos socio-culturales observados estando ahí. La función de escribir el texto sería más que una simple exposición de un saber, se trataría de una forma de pensar o, para decirlo de otro modo, el acto de escribir es simultáneo al acto de pensar (Cardoso de Oliveira, 2000).

Así, al preguntarse por el trabajo del antropólogo, este autor enfatiza el carácter constitutivo del mirar, el oír y el escribir en la elaboración del conocimiento antropológico. Estas tres etapas: mirar, oír, escribir, son actos cognitivos que constituyen una unidad irreductible. Nuestro mirar y oír no son ingenuos, antes bien, están disciplinados por nuestra propia disciplina formadora de nuestra manera de ver la realidad. Nuestra disciplina, entonces, condiciona las posibilidades de observación, de escucha y de textualización - a través de la escritura - siempre de conformidad con un horizonte que le es propio (Cardoso de Oliveira, 2000).

Al decir de este antropólogo, la escritura etnográfica alcanza su más alta función cognitiva en el estar aqui. Sin embargo, y si bien se trata de una escritura diferente, el escribir estando ahi también encierra - creemos - una importancia significativa a la hora de pensar y de pensarse - a uno mismo, a los otros - en el campo. Nos interesa entonces detenernos en esa otra instancia de escritura: aquella ligada a las instancias mismas de las situaciones en el terreno. A ese territorio, tal vez no demasiado explorado, que se configura cuando se abre la libreta de campo. Cuando se abre, sobre todo, en medio de la aldea, en medio de la ceremonia, de frente a los nativos, en el instante mismo de estar ahí.

Si las categorías con que aludimos a los actos no son ingenuas, entonces tal vez no se trate tanto de escribir como de anotar. Esto es, de fijar lo significativo. De elegir, de entre todo lo que se dice - de entre todo lo que podría escribirse -, aquello capaz de resultar revelador. En otras palabras: de saber escuchar, en medio de distintos acordes, la riqueza de un matiz. Pero no sólo se trata de una elección. También se trata, muchas veces, de un mandato. Las notas de campo a menudo cabalgan entre esa voluntad, más o menos propia, y esa suerte de sugerencia, más o menos explícita. Entre aquello que el antropólogo considera importante anotar y aquello que el otro cree importante que el antropólogo anote. Este trabajo busca reflexionar acerca de ese proceso puntual del trabajo de campo. No necesariamente para sondear en las cuestiones epistemológicas que hacen a la construcción de dichas notas, sino para ensayar algunas consideraciones sobre la relación que la acción misma de anotar configura entre observador y observado (donde el antropólogo no puede estancarse, a priori, en uno u otro término). ${ }^{1}$

Este trabajo se propone entonces un recorrido por nuestros ámbitos de análisis - el judicial y el policial $-^{2}$ y por lo que en ellos suscita tal actividad. Si las semejanzas entre ambos ámbitos resultan significativas, las diferencias 
no lo serán menos. Se trata entonces de poner en diálogo nuestros trabajos de campo y de ensayar, a partir del contraste de distintas experiencias, el esbozo de una lectura sobre el tono que adquiere, en estos terrenos, el acto mismo de registrar en el papel.

\section{La antropología, el anotar y la sospecha}

Uno llega al lugar donde hace su trabajo de campo. Trata, los primeros momentos, de pasar desapercibido. Trata de no molestar. Mejor dicho: consciente de que "molestar" es tan seguro como inevitable, trata al menos de que su intención de no disturbar le quede a todos clara. Luego, por ejemplo, se sienta. Presencia alguna situación. Si presa de estos devaneos disciplinares se queda, los primeros tiempos, un poco lejos o un poco aparte, pronto descubre los riesgos -en términos de observación- de este prurito. Los riesgos y la inutilidad, pues ciertas presencias, sobre todo la de un antropólogo en medio de la aldea, no tienen por qué ocupar el primer plano para ser insoslayables. $Y$ entonces, ya en el centro de la escena, ya en sus contornos, pero siempre presente, el antropólogo añade algo más a su presencia: anota.

Si los antropólogos resultamos ser, como alguien dijo, intrusos profesionales, la intromisión no se agota en esta mera presencia, en el solo estar, escuchar y observar. Hacemos algo más que estar ahí: registramos. ${ }^{3}$ Las notas de campo nacen desde el adentro, pero se inclinan también hacia el afuera: comunican al exterior lo que sucede al interior de un espacio. Divulgan. Son, si se quiere, la confirmación última de saberse observado. No sólo visto u oído; también aprehendido, fijado por largo tiempo en un instante. La escritura parece añadir algo de verdad irrefutable al proceso de observación, al convertir las palabras en hechos y los hechos - escritos - en materia de prueba. Por ello, quizás no estemos erradas si sugerimos que anotar puede asemejarse, en ciertos casos, a construir un panóptico desde el papel. A cimentar la advertencia de una mirada siempre presente y siempre inquisidora, que disciplina a quienes están sometidos a observación (Rosaldo, 1991). O mejor dicho: que ratifica, a partir de su existencia, la condición misma de ser observado.

Que el anotar pueda volverse una forma silenciosa de la inquisición requiere algunas consideraciones. Sería ingenuo, en este sentido, creer que la autoridad que reposa en el anotar obedece al solo hecho de plasmar ideas en un papel o se deriva de nuestra mera presencia de individuos. Si el anotar adquiere las connotaciones que adquiere se debe, en primera instancia, a un hecho insoslayable: somos científicos sociales. Es decir, somos, para las personas que conforman nuestro campo, científicos avalados institucionalmente (universidades, programas, agencias de investigación). Encarnamos la autoridad de la ciencia en general. De esa ciencia que instaura distancias cuasi-epistemológicas, al demarcar la existencia de un otro que se convierte en objeto, al recortarlo como universo de análisis y al elaborar, finalmente, sobre ese otro, un discurso autorizado (Tiscornia, 1992).

Pues si la ciencia da lugar a un saber asentado en conceptos, técnicas y objetos, engendra además, en ese mismo movimiento, sujetos de conocimiento y formas de verdad. Esto es, discursos de saber investidos de poder (Foucault, 1998). De aquí entonces que el proclamarse una ciencia sea, de hecho, un ejercicio de poder, ya que, al reivindicar para sí la cientificidad, otros saberes resultan descalificados (Smart, 1995).

Pero no solamente. Podríamos ir más allá y sostener que la autoridad que se deriva del ejercicio de la antropología le añade, al discurso de la ciencia, otro cariz. Cariz tal vez no ne- 
cesariamente propio de la antropología como de las ciencias del hombre, nacidas en estrecha vinculación a la temática del poder y el mantenimiento del orden. Y, por lo tanto, al estudio del otro como un objeto a indagar. En la construcción de ese otro como necesario de control y hasta de disciplinamiento, el saber de estas ciencias se instaura entonces como un espacio de intervención (Tiscornia, 1992; Pita, 1994).

Sin embargo, no escapa a nadie que, en el contexto de este surgimiento disciplinar, la antropología ha jugado un papel especial. Nacida en vinculación al interés imperialista mayormente británico y francés, nuestra disciplina ha quedado ligada a la empresa colonialista y a una expansión no sólo territorial sino ideológica, atada a una forma particular de conocimiento y de construcción de la información. Sobreimprimiendo a esta figura del antropólogo clásico la del funcionario colonial, la disciplina antropológica parece haber quedado asociada, en virtud a esta conjunción casi siempre poco sutil, al poder examinador, al escrutinio, a la auditoria y hasta al espionaje.

Algo de todo esto parece sobrevolar la sensibilidad de las personas que nos reciben en el campo:

A los pocos días de frecuentar un juzgado penal en particular, uno de los empleados judiciales me preguntó: “¿qué es lo que sos vos?”. Le respondí que era antropóloga e intenté explicarle brevemente lo que me interesaba investigar, pero ello no parecía tan importante como descubrir las "razones ocultas" de mi presencia:

EJ: ¿Pero vos qué estás haciendo acá?

D: Bueno, yo quiero ver cómo se tramitan ciertos conflictos familiares...

EJ: ¿Pero cómo hiciste para estar acá?

D: Le pedí permiso al Juez.

EJ: Ah, ¿vos lo conocés?

D: Sí, claro.

EJ: Pero ¿¿de dónde lo conoces?
D: No lo conocía, lo conocí ahora.

EJ: ¿Y él te dijo que vengas acá?, ¿para hacer qué?

D: No, él no me dijo, yo le pedí.

La pregunta no dicha pero sugerida ¿quién te manda? - parece sobrevolar los primeros contactos en el campo. Actitudes similares tuvieron lugar en el ámbito policial:

Durante mi estadía en la Escuela, mi presencia en sus aulas era, para los ojos de los alumnos, de por sí extraña. El hecho de ser mujer y no portar uniforme ni ser profesora revestía cierto carácter inusual. Pues en el espacio de estas escuelas, lo cerrado de la institución se intensifica. Por sus pasillos sólo circulan alumnos, profesores, instructores, directivos. Todos ellos, en su amplia mayoría, policías. Los pocos "civiles" son indefectiblemente docentes y guardan, generalmente, algún punto de contacto con la agencia policial. Circulan también, por estos espacios educativos, pocas mujeres. Unos y otras resultan, en estos contextos, visibles por minoritarios.

Pero al extrañamiento derivado de mi condición de mujer-civil-no profesora, se le sumaba un dato que no hacía sino multiplicarlo: yo insistía en presentarme en cada clase como una antropóloga haciendo trabajo de campo para su tesis de doctorado. Lo cual no era más que otra manera -exótica- de mantener abierta la sospecha. Pues si la institución no acostumbra a tener "extrańos" en su interior, menos aun acostumbra a tener académicos. ¿Qué era, en primer término, la antropología? ¿Y qué hacía, finalmente, una antropóloga, en medio de las aulas de la Policía?

No queremos sostener, con todo lo dicho, que este resabio que anuda el saber antropológico con cierto ejercicio inquisidor resulte evidente para las personas en el campo. No se trata tanto de una cualidad atribuible a la antropología como a las ciencias sociales en gene- 
ral. Lo importante, creemos, no reposa así en la delimitación disciplinar sino en los efectos percibidos del ejercicio de esta ciencia: la interrogación. Y aquí tal vez el antropólogo corra con suerte dispar, habituado como está a ser visto, ante los ojos de sus informantes, como aquel que curiosea, que busca información algunas veces incomprensible, ${ }^{4}$ que se entromete. Y que quizás por ello, suela ser visto por los otros no sólo como "intruso profesional" sino también como aquello que, alguna vez, le endilgaron a Viñuales sus informantes: "vampiro de experiencias" (2000, p. 32).

Mucho se ha llamado la atención sobre la importancia que revisten, a la hora de entender el papel que juega el antropólogo en el campo, las particularidades del ingreso a él. Sin detenernos largamente en este punto, sí nos interesa señalar que tales sensaciones de "sospecha" no pueden ser sino una compleja conjunción entre la presencia de alguien ajeno al campo $y$, tal vez más importante, el hecho de que tal presencia venga "habilitada" por aquel que, en la mayor parte de los casos, reviste algún tipo de autoridad. Así, y en lo que a nuestros ámbitos de análisis se refiere, el haber ingresado a tales burocracias a partir de la anuencia de sus máximas autoridades, convertía nuestras presencias en doblemente autorizadas: la autoridad del juez o del director de la escuela (o tal vez de alguien aún más arriba) parecía no poder despegarse de nuestro deambular por aulas u oficinas. La llevábamos donde fuéramos.

De este modo, a mitad de camino entre la "sospecha" y el desconocimiento respecto de lo que hace un antropólogo, las personas con las que nos relacionábamos en el campo, ensayaban para nosotras, durante los primeros tiempos, distintas identidades:

Había concertado telefónicamente una entrevista con un Juez penal. Durante la comunicación telefónica, le expliqué que era antropóloga y le comenté sobre el problema que estaba investigando; habiéndome presentado entonces, accedió a recibirme. Una vez en su despacho y en medio de la conversación, me sorprendió una pregunta: ¿vos estás en derecho o en psicología? "Soy antropóloga", respondí. Reflexionó en silencio unos segundos y prosiguió su explicación sobre las especificidades de los delitos dependientes de instancia privada.

Del mismo modo, las primeras veces que concurrí a algún juzgado penal, las personas que allí trabajaban asumían que era abogada, así, en ocasiones se dirigían a mí llamándome "Doctora”. Cuando había concertado alguna entrevista y llegaba al juzgado preguntando por ese agente judicial en particular, me respondían "Por aquí, Doctora.", "Pase, Doctora.", "Aguarde aquí por favor, Doctora." Me llamaba la atención que se me asignara a priori tal identidad, puesto que si bien en los juzgados abundan los letrados, no son ellos los únicos que los frecuentan, constantemente aparecen en las mesas de entradas tanto denunciados como denunciantes, así como también asistentes sociales y otros profesionales.

En el contexto de la Escuela policial, lo "sospechoso" de la presencia del investigador se resolvía apelando a una identidad que rozaba, con absoluta literalidad, los visos del espionaje: ${ }^{5}$

Aula 7, en la hora de Psicología. De repente, mediada la clase, G. se vuelve hacia la profesora y le pregunta qué era realmente lo yo hacía, si yo hacía realmente lo que había dicho que hacía. Lo miro directamente:

M: ¿Cuál es concretamente la pregunta?

G.: ¿Cuál es su función, señorita? - me dice, en abierto tono intimidatorio.

Le contesto lo que ya les había dicho, que estaba haciendo trabajo de campo para mi tesis de Doctorado en Antropología. Vuelve con la pregunta de si los estaba investigando a ellos. Al rato me dice que había venido alguien haciendo 
comentarios sobre mí, diciendo que yo hacía una investigación, pero para el Ministerio. Los demás apoyaron lo que decía, adhiriendo a la existencia del rumor. Les aclaro nuevamente que eso no era cierto, que yo ya les había dicho lo que hacía y que no trabajaba para ningún Ministerio.

El clima se pone tenso. Muchos empiezan a decirme que no le hiciera caso a G., otros le sugieren que deje la botella. Otro luego me explica que G. se sentía perseguido porque era Jefe de Destacamento y le tenía miedo al Ministerio. Me confirma también que fue un rumor de pasillo, surgido tal vez de ellos mismos, de charlar y comentarse: "mirá si va a ser cierto que está viniendo acá para hacer un trabajo, debe ser del Ministerio".

Así, cualquier presencia no fácilmente categorizable sólo parece poder resolverse a través de la apelación al propio ámbito. En el ámbito policial, tal vez a causa de esa separación tajante que la fuerza policial despliega entre ella y la sociedad civil, la circulación de éstos al interior de la fuerza - de aquellos que no guardan con ella ninguna relación de dependencia laboral o de parentesco - se ha consolidado como un hábito desacostumbrado. En este contexto, cualquier individuo que no porte uniforme es, cuanto menos, pasible de ser vinculado, de alguna u otra manera, a lo policial.

Así, si se declara no ser policía y se viste de “civil”, lo más probable es que no se lo sea, sino que se lo aparente. Después de todo, ¿cuándo se ha visto que la institución policial avale - o promueva- que alguien perteneciente a la sociedad civil, alguien que no tiene con ella ninguna ligazón profesional ni política, deambule por su interior? La remisión a la "familia policial" queda entonces formulada: lo que parece quedar de manifiesto es que, al interior de la agencia, todo civil puede ser, en realidad, alguien que - como el personal del Ministerio - pertenece.
Si nos resulta interesante traer a colación estas reflexiones es porque habilitan un mejor entendimiento no sólo del papel del antropólogo en la aldea y de la particularidad de las vinculaciones que en ella establece, sino, finalmente, de la compleja relación que llevan a éste y a la aldea a construirse mutuamente. Por ello, lejos de considerar que tales actitudes de recelo y adjudicación de identidades obedecen, en mayor o en menor medida, a una actitud de franca paranoia o de extrema desconfianza, conviene no olvidar que todos los sujetos "inocentes" antropólogos incluidos - estamos (o somos) políticamente situados. Es decir, que en un obvio deseo de explicarse quiénes somos, y siguiendo un propio marco de significación y entendimiento, somos continuamente posicionados por los otros. Esto es, continuamente tanteados, contrastados y entendidos. Así, el papel del antropólogo en el campo resulta, como sugiere Owens, "una empresa en colaboración, no completamente bajo el control individual del etnógrafo" (2003, p. 124). Es decir, la figura del antropólogo es también producto de las construcciones culturales, tanto propias como ajenas, que se producen en el campo.

Sin embargo, tal vez esta "duda" por quién uno es y por lo que uno hace, siempre presente en el trabajo etnográfico, adquiera, en el ámbito judicial y policial en el que discurre nuestro trabajo de campo, un cariz más acentuado. Señala van Maanen que en este tipo de organizaciones la sospecha es una creencia ocupacional inducida tan fuerte, que "el principal problema para una persona ajena (...) es evitar ser tomado como espía”. Tan arraigado es este sentido de sospecha - ilustra el autor - que muchas veces ha escuchado a los policías británicos decir, sólo en parte en broma, que "siempre que haya más de cinco canas juntos, podés estar seguro de que uno de ellos es un soplón" (1978, p. 317).

Comprender esto quizás requiera recordar que se trata, principalmente, de espacios es- 
tatales que combinan, de manera muy especial, una función punitiva con un alto índice burocrático. Son burocracias que ejercen, de manera legítima, la violencia y el castigo estatal. Sus operadores están, en primer lugar, habituados a la indagación. Esto es, a inquirir como herramienta de trabajo y a tomar, en base a esas inquisiciones, decisiones acerca del destino de las personas. Están también habituados a comerciar con la culpa y la sospecha, transformadas, sobre todo en el caso policial, en herramientas legitimadoras de la intervención (Eilbaum, 2004; Sirimarco, 2007).

En estos ámbitos, además, no sólo reina la indagación sino que el examen, basado en el análisis de los individuos y sus conductas antes que en la determinación de acontecimientos, está a la orden del día. Este es un saber que intenta determinar si los individuos se comportan "como se debe" - es decir, de acuerdo a las "normas" - y corregir sus comportamientos. No creemos exagerar si decimos que están habituados, por lo tanto, a hacer del otro un objeto de control.

Sumadas a estas características inherentes a la construcción de su función, no hay que olvidar que tales espacios se encuentran regidos, en tanto burocracias, por un alto grado de escriturización formal, signada por el uso especializado de un lenguaje técnico y normativo. No hay que olvidar, a este respecto, que fueron los procedimientos de examen los que, acompańados de un minucioso sistema de registro, hicieron entrar a la individualidad en un "campo documental”, en el mundo de los archivos, las fichas y los informes. El examen colocó a las personas en un "campo de vigilancia" y al mismo tiempo en una "red de escritura", lo cual redundó en su constitución como objetos analizables, como objetos y efectos de poder y saber (Foucault, 1989).

Toda burocracia registra cada detalle de lo que hace (Tiscornia y Sarrabayrouse Oliveira,
2004). ${ }^{6} \mathrm{Y}$ tal vez por ello, en tales ámbitos y en determinadas circunstancias, el antropólogo mismo sea sospechado de ser un jefe nhambiquara, un disputador de autoridades y competencias.

Así, si en dichos espacios el antropólogo observa y anota, es también él, a causa de este anotar, atentamente observado. En otras palabras, el anotar se vuelve una marca ineludible del trabajo del antropólogo, un rasgo que lo señala y que, en ocasiones, los otros no dudan en hacerle notar:

Luego de un mes de circular por los tribunales y hacer trabajo de campo en los juzgados, recibí mi primer sobrenombre. Estaba tomando notas de un expediente judicial cuando un empleado me interrumpió para pedirme que cambiara de escritorio: “Anita, ¿̨podés sentarte allá?”. Mientras asentía con la cabeza y cambiaba de ubicación, pregunté: “¿Cómo me dijiste?”. “Anita, Anita anota”, me respondió. A partir de entonces los empleados de ese juzgado penal comenzaron a llamarme "Anita, anota" y cuando pregunté por qué me llamaban así, me respondieron: "porque anotas y anotás"?

El anotar nos posiciona como antropólogos, como representantes de un saber-poder habilitado para la indagación y el conocimiento. La libreta de campo se transforma, por esto, en un objeto que condensa recelos y curiosidades. Desde preguntas directas por aquello que anotamos hasta intentos solapados por descubrirlo, la libreta del antropólogo parece delimitar el espacio de un enigma que los involucra pero que se les niega: qué anotamos, de todo lo que vemos y todo lo que pasa, pero sobre todo: para qué. Así pues, el cuaderno de campo, con sus anotaciones varias, pareciera ser el locus donde se cristaliza (¡o el fetiche que representa?) la autoridad y competencia que los jefes nhambiquara se disputan: 
Cierta vez un empleado judicial aprovechó mi ida al baño para tomar mi libreta de campo e intentar descifrarla. Cuando regresé a la oficina, lo encontré sosteniendo con una mano mi cuaderno y antes de que pudiera decir algo, él me preguntó:

EJ: ¿Qué anotas acá? No te entiendo la letra.

D: ¡Ah! ¿¿Me estabas leyendo el cuadernito?

EJ: Sí, quería ver qué escribís, pero no te entiendo la letra, por ejemplo acá: ¿qué dice?

Le expliqué que se trataban de notas sobre una audiencia que acaba de presenciar y entonces comenzó a listarme una serie de cuestiones que creía debía consignar en mi libreta.

La obligación a cierta reciprocidad parece envolver el acto de leer, sin más, las notas registradas en el cuaderno de campo. Después de todo, si uno como antropólogo tiene acceso a documentación y expedientes, ¿por qué aquel que los facilita no podría tener acceso a la libreta del antropólogo? Vinculada a sentidos de curiosidad, competencia y sospecha, la libreta de campo resulta, muchas veces, objeto de complicadas operaciones, que van desde espiar lo escrito por encima del hombro hasta -como ilustra el anterior extracto de campo- aprovechar ausencias para intentar descifrarlo. A veces las operaciones se tornan menos sutiles. Valga si no un ejemplo de lo sucedido durante el trabajo de Herbert en el Departamento de Policía de Los Ángeles. Éste relata que, cierta vez, "dos oficiales conspiraron para sacarme la libreta que usaba para registrar mis impresiones. Uno vino desde atrás e inmovilizó mis brazos mientras el otro arrancaba de mis manos la libreta" (2001, p. 306). Ésta se había transformado, parece, en un objeto tan amenazador como misterioso. ${ }^{8}$

En aldeas tan particulares como las mencionadas, el anotar puede transformarnos -decíamos- en un jefe nhambiquara. Esto es, en aquel que puede pasar de observador a observado, como en un infinito juego de espejos, que al devolver una imagen de autoridad no hace más que (re)crearla. Y como aquel que puede subvertir, gracias a la construcción de una red de interrogación y de escritura, el campo mismo de vigilancia, haciendo que los otros, cuyo métier es el control y la sospecha, se sientan asimismo controlados.

Los alumnos de la Escuela, luego de una jornada de copiosas notas de campo, solían increpar a los profesores en una difusa manera de increparme a mí: “¿La chica nos va a decir después qué opina? Porque ella anota, anota”. Y remataban con la suspicacia de rigor: "a ver si después es del Ministerio”.

Las palabras de estos alumnos nos devuelven al tema del espionaje. Y nos permiten volver a detenernos en la manera en que se decodifica, al menos desde las agencias analizadas, la labor del antropólogo en el campo: sus interrogaciones, sus anotaciones, sus preguntas. Cierto episodio merece rescatarse en tal sentido:

Charlaba con un par de alumnos luego de terminada una clase. Uno de ellos parecía no entender la vinculación entre la Antropología y mi trabajo de campo en la Escuela. No terminaba de entender a qué me dedicaba, qué quería ver ahí. Mis muchas - y se conoce que no muy buenas - explicaciones no contribuían demasiado a su comprensión. Entonces el compañero a su lado, que hasta ese momento había permanecido escuchando en silencio, lo ayudó a entender con una analogía: "como si fuera Inteligencia nuestra”.

Tal vez la antropología - su visualización en tanto práctica en el campo - no esté tan alejada, para muchos (sobre todo informantes), de un sentido de investigación guiado por algún afán de vigilancia y de control. Pero no solamente. Muchas veces, la labor antropológica es 
vinculada también a otros sentidos, más cercanos a una actitud de denuncia y acusación.

En toda presentación en el campo los antropólogos solemos resaltar el hecho de que nuestras anotaciones tienen sujetos anónimos puesto que lo que nos interesa tiene que ver con problemáticas sociales y no con personas particulares. Si bien la aclaración es importante, no sólo porque es cierta sino porque las más de las veces es la que asegura nuestra permanencia en el lugar, no siempre resulta del todo suficiente:

Aún cuando no gozaba de un "libre acceso" en los juzgados, siempre recaía en mí una cierta sospecha, cuando no una recomendación: "si te llegás a encontrar con una "bomba", te pido que me avises”. A primera vista dicha recomendación de no revelar aquello que podría poner a un juzgado en falta, podría tener más sentido, tal vez, para un colega, un auditor, un enviado del Ministerio de Justicia o un evaluador de una ONG que para un antropólogo comprometido con el anonimato de sus datos y preocupado por problemáticas sociales que trascienden a sujetos particulares. Vista más de cerca, la recomendación no hacía más que poner de relieve, una vez más, la decodificación de mi presencia según la propia matriz de significación de los actores; es decir, la advertencia tenía sentido en relación con el propio ámbito del derecho.

Así pues, la sospecha que puede despertar el antropólogo en el campo (de la burocracia penal) puede que esté relacionada también con cuestiones que hacen a las distinciones entre la práctica de los antropólogos y la de sus informantes, donde unos y otros tienen diferentes miradas e intereses respecto de los hechos. Como sugiere Kandel (1992), el derecho deriva su razón de ser de la necesidad de asignar responsabilidad social, la antropología no; mientras que el propósito del derecho es determinar la responsabilidad en las disputas y dirigir la acción que corrija, castigue, cambie o recompense el daño, la antropología busca explicaciones por fuera de la responsabilidad de los individuos particulares, su propósito es proveer de una comprensión explicativa de la realidad sociocultural.

Si abogados, jueces, policías y antropólogos tenemos diferentes intereses y miradas sobre los hechos, esas diferencias, en tanto formas de hacer y actuar, juegan en la interpretación que los informantes realizan respecto de la presencia del antropólogo en el campo. Decíamos más arriba que antes de considerar las actitudes - generalmente de recelo - ocasionadas por nuestra presencia en el campo como simples respuestas paranoides o de desconfianza, ellas nos hablan de algo más, forman parte de la construcción del papel del antropólogo que, como otras formas de producción cultural de significado, es también una empresa colectiva (Owens, 2003). Estas actitudes tienen que ver entonces con el lugar que, siguiendo el propio marco de significación, nos asignan nuestros interlocutores en el campo y responden, en parte, al propio horizonte de sentido, al mundo particular del que participan; al ámbito que, a través de sus prácticas y saberes, crean y recrean.

En estos ámbitos, cuestiones relacionadas con el secreto, el silencio y el manejo de la información cobran especial importancia. Así, a la manera de un velo que esconde aquello que no se puede ver (que no se puede conocer), la existencia/presencia del secreto comunica la existencia de un conocimiento que no resulta universalmente disponible sino que, por el contrario, privilegia la particularización de su acceso y la exclusividad de su información. El secreto y el silencio se convierten así en la exaltación suprema de la situación de apartamiento, separando los legos de los arcanos, aislando un adentro recóndito e impenetrable de 
un afuera tan ignorante como ofensivo (Weber, 1964; Simmel, 1977).

Quizás por ello en estos espacios el antropólogo, y especialmente cuando anota, cuando fija los hechos a través de la escritura, despierte tantas suspicacias. No sólo porque disputa autoridad y competencia, alejándose -aunque nunca del todo- del simple "lego", sino también porque parece amenazar, por su sola presencia, el mantenimiento del secreto. Porque no pertenece y, sin embargo, está ahí, y por ello también, por no pertenecer, algunos espacios le están vedados:

Presenciaba un juicio oral y público por un caso de incumplimiento de los deberes de asistencia familiar cuando sorpresivamente el juez dijo: "quiero hablar a solas con el fiscal y la defensa". "A solas" era sin mi presencia puesto que la única persona a la que se le requirió que se retirara fue a mí. Imputado, víctima, defensa, fiscal, juez y secretario permanecieron en el recinto. Minutos después hicieron salir al imputado, quien apenas media hora después volvió a ingresar a la sala.

Y es que tales ámbitos, el policial tanto como el judicial, no son sólo burocracias penales. Son también -como mucho se ha enfatizadoespacios cerrados sobre sí mismos, más o menos autónomos, con intereses particularizados, aglutinados en torno a metáforas de comunidad (la "familia judicial", el "cuerpo policial"). En ellos, sus miembros se vuelven cuerpos corporados: cuerpos atravesados y modelados por las directrices de una determinada corporación, de una determinada diagramación social de la realidad, donde la producción de cuerpos corporados resulta así indisociable de la delimitación de un "afuera". Esto es, de la demarcación de un dominio de abyección - en su sentido de rechazo - representado por personas no incorporadas, que marcan, en virtud a esta semiótica de la exclusión, los límites mismos de la autodefinición del cuerpo social (Ferguson, 2000; Butler, 2002).

\section{El antropólogo en la aldea de la burocracia penal ${ }^{9}$}

Decíamos que "estar ahî" despierta en los que cotidianamente están allí la curiosidad, cuando no la sospecha y el recelo. Si ello es así en cualquier "aldea", en la penal y burocrática, acostumbrados, como están, a sospechar, el antropólogo es objeto de cercano escrutinio, despierta suspicacias y dispara el interrogante acerca del "intruso profesional”: ¿quién es?, ¿qué está haciendo aquí?, ¿por qué está aquí?

Nos gustaría matizar esta afirmación. Pues si esto que decíamos puede ser válido en los primeros tiempos del trabajo de campo, no es menos cierto que, cuando al investigar una determinada problemática el antropólogo permanece un tiempo más o menos prolongado en una aldea en particular, su permanencia implica, entre otras cosas, el establecimiento de distintas y cambiantes relaciones con los sujetos con los que interactúa. Así, la construcción colectiva del papel del antropólogo en una aldea determinada no es un proceso cerrado y absoluto, al igual que no lo son las relaciones que el etnógrafo va tejiendo en la construcción de su campo. Y justamente debido a ellas, dicha construcción sufre modificaciones, es puesta a prueba y adquiere nuevos matices.

Pasada la novedad de mi práctica [en las Escuelas policiales], me convertí, para ellos, y según sus propias palabras, en la agenda: el locus ante el cual contrastar lo dicho o no dicho por el profesor. Ya se tratara de refrescar lo visto la clase anterior, o de corroborar si el docente había hecho referencia o no a cierta temática, yo parecía ser, para ellos, una suerte de registro vivo. 
Si se quiere, una especie de amanuense. Pero no sólo de las cuestiones curriculares. Antes bien, de todo aquello que hacía a la cotidianeidad del curso. Bastaba que un chiste asomara, o que alguien dijera algo (que se creyera) comprometido, para que uno de los alumnos me mirara, desde su rincón del aula, y me dijera, como con un guiño: "anote, Doctora". ${ }^{10}$

Puede creerse que esta suerte de mandato implica, de manera unívoca, la confirmación más directa del lugar del antropólogo-espía. Es decir, de aquel que está allí para observar, controlar, calibrar lo dicho y lo callado y, finalmente, tomar debida nota de lo sucedido. Pero semejante apelación al registro guarda otros sentidos. Con el correr del tiempo compartido, tal requerimiento se volvía, más bien, el otorgamiento de un permiso. $\mathrm{O}$, en el mejor de los casos, la asunción de una tarea ya revelada como "inofensiva”. No era sólo el antropólogo el que anotaba: eran ellos los que, señalándole aquellos puntos salientes de discursos o actitudes, lo consentían y, por lo tanto, lo propiciaban. Lo amenazante, creemos, se había vuelto cotidiano; lo sospechoso, esperable.

$\mathrm{Y}$ es en este pasaje de lo amenazante a lo cotidiano -de la sospecha a la aceptación- donde se revela el tiempo transcurrido en la aldea. Donde se revela el cómo de la presencia en el terreno y de las relaciones que se tienen con unos y otros. Donde se revela, en suma, la construcción del campo. Así, tal vez no sea fortuito que tal aceptación del antropólogo en la aldea se ratifique a partir de una de sus actividades representativas: el anotar.

Sostiene Rapport (1991) que el acto de escribir notas de campo no debe describirse como algo que simplemente abstrae a los antropólogos del campo y los liga a una actividad en la academia (podríamos decir: a un desempeño de carrera profesional donde las notas podrían considerarse materia prima). Antes bien, las notas de campo son eso que, de manera simultánea, sumerge a los antropólogos profundamente en una comunidad y en el self en que ahí se transforman. Pues si el estar ahi no alude simplemente a una presencia física (sino a la aceptación que vuelve posible esa presencia), idéntico camino recorren las notas de campo. Es el hecho de estar ahi, de manera continua y cotidiana, lo que finalmente nos posiciona $a h i{ }^{11}$ En este sentido, las construcciones cambiantes del papel del antropólogo en el campo hablan de las distintas relaciones que aquél establece con sus interlocutores, relaciones que junto con el conocimiento local adquirido, creemos, permiten una cierta "incorporación" del investigador a la aldea en cuestión. Así, y sobre todo en ámbitos como los que trabajamos, tal vez no sea arriesgado proponer que cuando las notas de campo viran de intrusión a chanza, uno está finalmente ahi (o por lo menos cerca):

Luego de un cierto tiempo de trabajo de campo en un juzgado penal (donde me llamaban Anita Anota) me familiaricé con el trabajo que allí se realizaba, con el espacio de las oficinas, las personas que trabajaban en ellas. Dejaba mi cuaderno de campo en algún escritorio mientras realizaba alguna otra actividad y, a diferencia de unos meses atrás, ya a nadie parecía importarle, ni el cuaderno, ni mis anotaciones. Sin embargo, importaba, aunque de una manera diferente. Un día encontré en mi cuaderno de apuntes una nota: "Anita, anotá, cuidate, te estoy vigilando. Reitero, cuidate".

Se ha dicho - afirma García Canclini -

que el antropólogo es un espía chismoso, y en este sentido se aproxima al hacker, pero su conocimiento no deriva de la obtención astuta de una clave sino de la familiarización prolongada con redes complejas de interacciones y significados (2006). 
Incorporado a la rutina cotidiana, el antropólogo se torna objeto de pedidos ("la agenda") y hasta de chistes como el reseñado más arriba, en el que, en clave de amenaza, la broma viene a subvertir el lugar del antropólogo-jefe nhambiquara: el intruso profesional no parece ya ser amenazante, ni tampoco sospechoso.

Mencionábamos en el apartado anterior que, al comienzo de su investigación sobre identidades lésbicas, Viñuales era tildada, por sus informantes, de "vampiro de experiencias". Sólo luego de muchos meses de participación y trabajo voluntario pasó de ser el "ojo exterior" a ser la "presunta heterosexual", "la ricitos" y, finalmente, a ser simplemente "Olga". Lo gradual de la incorporación se refleja en los apelativos. También nosotras pasamos de ser "la antropóloga" o "la doctora" a ser Anita o ser la agenda. Lo que va de uno a otro apodo es la paulatina aceptación de la presencia del antropólogo en la aldea. O mejor dicho: lo que se pierde de uno a otro apodo es esa aura de desconfianza y distancia que la figura del antropólogo suscita.

Si antes éramos un "otro", el tiempo y las relaciones nos van acercando a la conformación de un núcleo de pertenencia donde ya no somos tan ajenos. No se trata, es claro, de un "nosotros"; esto es, de una asimilación completa. Se trata, más bien, de esa cuota de inclusión que permite equilibrar la distancia. Es decir, que permite minimizar ese intervalo que nos separa de la comprensión de los otros. Que permite, en palabras de Geertz,

producir una interpretación de la forma en que vive un pueblo que no sea prisionera de sus horizontes mentales, como una etnografía de la brujería escrita por una bruja (1994, p. 75).

En este sentido, el éxito del trabajo de campo no es volvernos nativos, sino dejar de ser extraños.
Es ahí donde se anuda la riqueza de ser Anita. En demostrarnos que si la comprensión del otro tal vez pueda prescindir de la afinidad, no puede lograrse desde la distancia. Pero este proceso de incorporación, común a todo campo, tiene, en las instituciones que analizamos, algunos otros ribetes que nos gustaría destacar.

Mucho se ha enfatizado, en el análisis de estas burocracias, sobre su extremo hermetismo y su resistencia a la hora de conceder información. Estos rasgos, vinculados al alcance y poder que revisten estas agencias en la sociedad, se han conjugado para hacer de ellas un locus de investigación casi siempre exotizado. En parte porque los campos policial y judicial son visualizados, muchas veces, como espacios de cierta "peligrosidad" (Eilbaum y Sirimarco, 2006). Llegar a ser Anita se vuelve, en tales casos, una empresa importante, que permite desmitificar esta aura de espacio secreto y cerrado que los rodea. Taussig (1996) nos recordaría que el fetichismo del poder esconde un vacío, pues su sacralidad no se ubica en el centro mismo sino más bien en las fantasías de los marginados sobre el secreto del centro. Tal vez porque sólo se puede reconocer al centro desde un lugar que no lo sea: no puede haber centro sin que medie la distancia. La comprensión del otro implica tanto acortar ese trayecto como esa sacralidad, pues pareciera no poder existir ese lugar inaccesible si en el proceso de entendimiento se involucra el acercarse.

Llegar a ser Anita implica, además, dejar de sobrevalorar, en estas instituciones, lo penal por sobre lo burocrático:

En la marcha por los treinta años pasados desde la última dictadura militar, tratábamos, un grupo de personas, de llegar a la Plaza de Mayo por una de las calles laterales. Carros blindados, patrulleros y policías descansaban, apostados, sobre la calle Bartolomé Mitre. A unos metros, a una distancia digamos que prudencial - dis- 
tancia que era tanto espacial como simbólica -, varios hombres charlaban en rueda. A ninguno de los transeúntes se le escapaba que se trataba de personal de Brigadas. Escucho, mientras los pasábamos, el comentario de una mujer delante mío: "éstos deben estar fichando a todo el que pasa”. Una amiga, también escuchándolo, (le) replica: "deben estar hablando del partido de River".

Este mínimo hecho condensa lo que intentamos presentar en estas páginas: la construcción de una determinada imagen del otro mediada - y construida - desde la distancia. Al primer comentario, surcado por sospechas de permanente control y espionaje, el segundo le devuelve una imagen menos aprensiva. Si se quiere, menos claustrofóbica. Lo que se dirime, entre uno y otro, no es un simple intercambio de opiniones. Es, antes bien, el despliegue de dos modalidades distintas de mirar al otro. Lo que se dirime, mejor dicho, es la posibilidad misma de diferentes miradas - una conspirativa, una cotidiana - y la posibilidad, por ende, de distintos entendimientos.

Si algo intentamos plantear en estas páginas es, entonces, la importancia de intentar una mirada que no resulte opacada por la distancia. De intentar ver más allá de los prototipos: de investigar qué hay del otro lado de la imagen que se construye del otro. De vencer el espacio, en suma, que nos separa de ese otro y de su entendimiento.

Ser aceptado e incorporado en el ahi es lo que permite finalmente el buen trabajo antropológico; si se quiere, la buena etnografía. De aquí entonces la importancia de preguntarnos por los sentidos y las relaciones que el anotar - en tanto instancia de escritura privilegiada en el ahi-desencadena en el campo. El rechazo que suscita, la sospecha y la curiosidad que despierta y, por último, las particularidades que conlleva la incorporación del antro- pólogo a esa cotidianeidad. ¿¿De qué nos habla todo esto? Si estos tipos de reacciones son las que la acción misma de anotar implica en casi cualquier campo, el presente trabajo pretende colocar una pregunta adicional: ¿qué particularidades adquiere, este anotar, en campos como los nuestros?

\section{Anita Anota. The anthropologist in the pe- nal and bureaucratic village}

abstract Field notes often fluctuate between what the anthropologist considers important to write and what others believe is important for him to write. This article intends to reflect on this specific process of fieldwork. Not necessarily to inquire about the epistemological issues that are related with the act of taking notes, but to try out some considerations about the relation that this very act shapes between the observer and the observed. This article proposes a trajectory into the authors' fields of research - the judicial and police fields - and through the questions raised by such act of taking notes in these contexts. The purpose is to establish a dialogue between both fieldworks and to sketch a certain interpretation of the impact caused by the very act of taking notes in these fields by contrasting different experiences.

keywords Fieldwork. Field notes. Taking notes. Judicial field. Police field.

\section{Notas}

La autoridad y la autoría etnográfica fueron temas ampliamente trabajados desde la antropología posmoderna, con la exploración de nuevas formas de escritura que reflejaran la polivocalidad y la relación entre autor, escritor, lector y asunto; formas de escritura experimentales que pudieran asimismo mostrar las relaciones de poder contenidas en cualquier trabajo etnográfico (Marcus \& Fischer, 1986; Clifford \& Marcus, 1986). Si bien desde estos lineamientos 
existe una amplia producción académica que no desconocemos, no es nuestra intención, en este trabajo, entablar un diálogo con las reflexiones de la antropología posmoderna.

2 Lo presentado en este trabajo se enmarca en nuestros respectivos proyectos de investigación doctoral. Deborah Daich investiga la administración judicial penal de conflictos familiares. Mariana Sirimarco trabaja con cuestiones ligadas a la formación policial en las Escuelas de ingreso a la institución policial y con la construcción, en tales períodos formativos, de un determinado sujeto policial. Los extractos relativos a cada investigación se señalan diferencialmente en el texto y corresponden a trabajos de campo realizados entre el año 2004 y 2007. Hemos elegido mantener, en ellos, la narración desde la primera persona, para conservar su calidad de registros de campo. Hemos optado asimismo por no dar detalles de los lugares institucionales donde transcurren tales situaciones. Esto por entender que, si bien los eventos transcurrieron en aulas y oficinas puntuales, bien hubieran podido ocurrir en cualquier Juzgado o en cualquier Escuela. Para una profundización de las investigaciones mencionadas pueden consultarse: Daich (2008, 2008b, 2008c), Sirimarco (2004, 2005, 2006).

3 No se trata de reducir la labor antropológica al mero hecho de anotar. Tampoco de soslayar, en el trabajo de campo, otras capacidades distintivas ligadas por ejemplo al escuchar, hablar o preguntar (como mencionábamos en el apartado anterior). Sin dejar de considerar estas habilidades como una totalidad interrelacionada, se trata de focalizar el eje de este artículo en uno de los componentes de dicho trabajo de campo.

4 Nos referimos con esto a ese tipo de información que, relevante para el antropólogo, el informante no termina de considerar demasiado importante.

5 Respecto de la identidad del antropólogo en relación con la sospecha de espionaje y la imagen de antropólogo-espía, ver Guber 2001 y 2004. Para otras derivaciones de la conjunción antropología-espionaje, sobre todo en contextos políticamente complejos, ver Owens 2003 y Wright 2007.

6 Es interesante destacar, como sugieren las autoras, que "si Michel Foucault descubrió la opresión que la "sociedad del expediente" inflinge sobre los habitantes de un estado, al espiar y registrar sus más nimias acciones, Stanley Cohen advierte, en cambio, que esos mismos registros al convertirse en documentos, pueden transformarse en la descripción y la prueba precisa de los crímenes del dominio totalitario" (Tiscornia y Sarrabayrouse Oliveira, 2004, p.65). Así, si la obsesión burocrática por el registro se traduce en una arista opresiva de las sociedades, es también ella la responsable de crear las pruebas que puedan desafiarla así como los materiales de análisis disponibles para las ciencias sociales.

7 "Anita, anote" era una frase que utilizaba uno de los personajes encarnados por el cómico argentino Pepe Biondi en el programa televisivo "Viendo a Biondi" emitido en los años 60 y repetido en las décadas siguientes. Cuando una colega, María Victoria Pita, me recordó este hecho, pregunté, a los que así me apodaron, si el sobrenombre era en homenaje a ese viejo sketch y, mostrando cierta sorpresa, me respondieron: "No, no, es porque no parás de anotar".

8 Si la libreta de campo puede volverse un objeto de recelo, lo mismo (o tal vez más) puede decirse del grabador. Si bien su utilización no es motivo de este trabajo, por entender que ésta implica contextos y momentos un tanto distintos del trabajo de campo, nos gustaría contar una pequeña anécdota que ilustra claramente hasta qué punto estos elementos se entienden como herramientas profesionales, y delimitan, por lo tanto, complejos juegos de intimidaciones, atribuciones y competencias: "Recreo en la Escuela. Vuelvo al aula 2, a pedir voluntarios para una charla. Luego de un silencio tan largo como incómodo, B. se ofrece. No faltan las risas y los chistes, al mejor estilo de colegio secundario. Llueven las recomendaciones para el candidato: al menos, que yo le pague el almuerzo. En medio de las bromas, le pregunto si no tiene problemas en que la charla sea con grabador. Me contesta algo que suscita la carcajada general: “ ¿y yo puedo ir con una pistola con silenciador?”.

9 Es hora de explicitar que el uso del término "aldea" para referirnos al campo judicial-policial no intenta ser una transposición literal de las categorías de la antropología clásica, sino más bien la utilización de sus herramientas para pensar y dar cuenta de distintas situaciones y problemáticas. En este sentido, vale la pena recordar, siguiendo a Geertz (2000), que los antropólogos no estudiamos aldeas, sino en aldeas. Es decir, estudiamos lo que construimos como problemas que corresponden a "campos" también construidos, donde el uso de conceptos propios de la antropología clásica puede ser útil para pensar problemas característicos de sociedades con una organización estatal y burocrática desarrollada (Eilbaum 
\& Sirimarco, 2006). En una línea similar de aclaraciones, cabe mencionar que el término "informante" juega claramente con el uso antropológico clásico y el uso que presenta en el ámbito judicial-policial, aludiendo así a los varios sentidos con que, en el campo, se teje la construcción del otro.

10 El tratamiento de "doctora" implica, es claro, una deferencia. En el ámbito policial las profesiones son debidamente jerarquizadas, y el ejercicio del derecho se convierte en la posesión de un status privilegiado.

11 No se trata de afirmar, por supuesto, que la mera presencia física en el terreno conlleva, con el tiempo, la aceptación. Se trata de señalar, por el contrario, que éste es un proceso dependiente de la modalidad de las relaciones en el campo.

\section{Referências bibliográficas}

AGAR, Michael. Stories, background knowledge and themes: problems in the analysis of life history narrative. American Ethnologist, vol.7, n.2, p. 223-239, 1980.

BUTLER, Judith. Cuerpos que importan. Sobre los límites materiales y discursivos del "sexo". Traducción de Alcira Bixio. Buenos Aires: Paidós. 2002.

CARDOSO DE OLIVEIRA, Roberto. O Trabalho do antropólogo. Brasília: Paralelo 15, São Paulo: Editora UNESP. 2000.

CLIFFORD, James; MARCUS,George E.(eds.). Writing culture: The Poetics and Politics of Ethnography. Berkeley and Los Angeles: University of California Press, 1986.

DAICH, Deborah. Buena Madre. El imaginario maternal en la tramitación judicial del infanticidio. In: TARDUCCI, Mónica (Org.), Maternidades del siglo XXI. Buenos Aires, Espacio Editorial, 2008. p. 6186.

De objetos y prácticas en el mundo de la Justicia. Los efectos judiciales. Antropolitica, PPGAS, Universidad Federal Fluminense, n.23, 2008b. En prensa.

Te conozco Mascarita. Prácticas de identificación en el mundo judicial penal. Avá Revista de Antropología, Programa de Posgrado en Antropología Social, Universidad Nacional de Misiones, n. 12, 2008c. En prensa.

EILBAUM, Lucía. La sospecha como fundamento de los procedimientos policiales. Cuadernos de Antropología Social, Instituto de Ciencias Antropológicas, Universidad de Buenos Aires, vol. 20, p. 79-91, 2004.
EILBAUM, Lucía; SIRIMARCO, Mariana. Estudios sobre la burocracia policial y judicial, desde una perspectiva etnográfica. In: WILDE, Guillermo; SCHAMBER, Pablo (Comps.), Culturas, comunidades y procesos urbanos contemporáneos. Buenos Aires: Paradigma Indicial, 2006. p. 103-124.

FERGUSON, Dean. The body, the corporate idiom, and the police of the unincorporated worker in Early Modern Lyon. French Historical Studies, vol.23, n.4, p. 545-575, 2000.

FOUCAULT, Michel. Vigilar y castigar. Traducción de Aurelio Garzón del Camino. Buenos Aires: Ed. Siglo XXI. 1989.

. La verdad y las formas jurídicas. Traducción de Enrique Lynch. Barcelona: Gedisa. 1998.

GARCÍA CANCLINI, Néstor. ¿Dónde está la caja de herramientas? Cambios culturales, jóvenes y educación. 2006. Seminario internacional: "La formación docente en los actuales escenarios: desafíos, debates, perspectivas". Universidad de La Matanza.

GEERTZ, Clifford. La interpretación de las culturas. Traducción de Alberto Bixio. Barcelona: Gedisa. 2000.

Conocimiento local. Ensayos sobre la interpretación de las culturas. Traducción de Alberto López Bargados. Buenos Aires: Editorial Paidós. 1994.

GUBER, Rosana. La etnografía, método, campo y reflexividad. Bogotá: Grupo Editorial Norma. 2001.

El salvaje metropolitano. Reconstrucción del conocimiento social en el trabajo de campo. Buenos Aires: Paidós. 2004.

HERBERT, Steve. From spy to okay guy: trust and validity in fieldwork with police. Geographical Review, vol. 91, n. 1/2, p. 304-310, 2001.

KANDEL, Randy Frances. How lawyers and anthropologists think differently. Six differences in assumptions and outlook between anthropologists and attorneys. Napa Bulletin vol. 11, n. 1, p. 1-81, 1992.

NAGORE, Josefina. "La parodia de Ovidio. In Petronio, Sat., C. 126”. AFC, XV, p. 167-179, 1997.

LÉVI-STRAUSS, Claude. Tristes trópicos. Traducción de Noelia Bastard. Buenos Aires: Eudeba, 1973.

MARCUS, George E.; FISHER, Michael M. J. Anthropology as Cultural Critique: An Experimental Moment in the Human Sciences. Chicago and London: University of Chicago Press, 1986.

MARCUS, George. Epílogo: la escritura etnográfica y la carrera antropológica. In: CLIFFORD, James; MARCUS, George (Eds.), Retóricas de la Antropología. Madrid: Júcar Universidad, 1991. p. $357-$ 363. 
OWENS, Geoffrey Ross. "What! Me a spy? Intrigue and reflexivity in Zanzíbar. Ethnography, vol. 4, n.1, p. 122-144, 2003.

PITA, María Victoria. Horizontes artificiales. Acerca de la posibilidad de una lectura crítica desde la antropología política. In: IV CONGRESO ARGENTINO DE ANTROPOLOGÍA SOCIAL, Universidad Nacional del Centro, Facultad de Ciencias Sociales e Instituto de Investigaciones Antropológicas, Olavarría, 1994.

RAPPORT, Nigel. Writing fieldnotes: the conventionalities of note-taking and taking notes in the field. Anthropology Today, vol.7, n.1, p. 10-13, 1991.

ROSALDO, Renato. Desde la puerta de la tienda de campaña: el investigador de campo y el inquisidor. In: CLIFFORD, J.; MARCUS, G. (Eds.), Retóricas de la antropología. Madrid: Júcar, 1991, p. 123-150.

SIMMEL, Georg. Sociología I: estudios sobre las formas de socialización. Traducción de José R. Pérez Bances. Madrid: Revista de Occidente, 1977.

SIRIMARCO, Mariana. Marcas de género, cuerpos de poder. Discursos de producción de masculinidad en la conformación del sujeto policial. Cuadernos de Antropología Social, Instituto de Ciencias Antropológicas, Universidad de Buenos Aires, vol. 20, p. 61-78, 2004. . Milongas: pedagogía del sufrimiento. Construcción del cuerpo legítimo en el contexto de socialización policial. Interseçôes, Universidad Estadual de Rio de Janeiro, año 7, n. 2, p. 53-67, 2005.

El ingreso a la institución policial. Los cuerpos inviables. Anuario de Estudios en Antropología Social 2006, CAS-IDES, p. 97-110, 2006.
Indicios. Semiología policial del cuerpo de los “otros”. Ultima Ratio, Lumen Juris editora, São Paulo, año 1, vol.1, p. 199-229, 2007.

SMART, Carol. Feminism and the power of law. Londres y Nueva York: Routledge. 1995.

TAUSSIG, Michael. Schopenhauer's beard. In: BERGER, Wallis; WATSON (Eds.), Constructing masculinity. New York: Routledge, 1995. p. 107-114. Un gigante en convulsiones. Barcelona: Gedisa, 1996.

TISCORNIA, Sofía. Antropología política y criminología. Acerca de la construcción de dominios en el control de la "otredad". Publicar. Antropología y Ciencias Sociales, Buenos Aires, año 1, n.1, p. 53-68, 1992.

TISCORNIA, Sofía; SARRABAYROUSE OLIVEIRA, María José. Sobre la banalidad del mal, la violencia vernácula y las reconstrucciones de la historia. In: TISCORNIA, S. (Comp.), Burocracias y violencia. Estudios de antropología juridica. Buenos Aires: Antropofagia, 2004, p. 63-79.

VAN MAANEN, John. Epilogue. On watching the watchers. In: MANNING, Peter; VAN MAANEN, John (Eds.), Policing: a view from the street. Santa Mónica: Goodyear Publishing Company, 1978, p.309-349.

VIÑUALES, Olga. Identidades Lésbicas. Discursos y prácticas. Barcelona: Ed. Bellaterra. 2000.

WEBER, Max. Economía y sociedad. Esbozo de sociología comprensiva. Traducción corregida por F. Atria. Buenos Aires, México: Fondo de Cultura Económica. 1964.

WRIGHT, Susan. Spying and fieldwork. A response to Heike Schaumber. Anthropology Today, vol. 23, n.1, p. 28-28, 2007.

\title{
autoras Déborah Daich
}

Licenciada em Ciências Antropológicas da Universidade de Buenos Aires

Mariana Sirimarco

Doutora em Ciências Antropológicas da Universidade de Buenos Aires

\author{
Recebido em 15/02/2009 \\ Aceito para publicação em 06/11/2009
}

